\title{
ENTEROVIRAL INFECTION OUTBREAK IN THE REPUBLIC OF BELARUS: PRINCIPAL CHARACTERISTICS AND PHYLOGENETIC ANALYSIS OF ETIOLOGICAL AGENTS
}

\author{
Tamara V. Amvrosieva ${ }^{1}$, Natallia V. Paklonskaya ${ }^{1}$, Aliaksei A. Biazruchka ${ }^{1}$, Olga N. Kazinetz ${ }^{1}$, Zoya F. Bohush ${ }^{1}$, \\ Elena G. Fisenko² \\ ${ }^{1}$ Research Institute for Epidemiology and Microbiology, Republic of Belarus \\ ${ }^{2}$ Hygiene and Epidemiology Centre of Minsk, Republic of Belarus
}

\begin{abstract}
SUMMARY
For the last decade enterovirus outbreaks were registered in all of six districts of Belarus. Two of them, reported in 1997 (in Gomel) and in 2003 (in Minsk), were the most extensive and involved 461 and 1,351 patients respectively. Virus ECHO 30 was identified as the dominant etiologic agent of the outbreak in 1997 whereas co-circulation of ECHO 30, ECHO 6 and Coxsackievirus B5 took place in 2003. Analysis of clinical manifestations during the Minsk outbreak revealed unusually high rate of severe clinical forms of infection including aseptic meningitis, encephalitis and myocardial disorders. Epidemiologic observation was ordinary for enterovirus epidemics in temperate climates: the peak of the outbreak was recorded during summer - autumn period of 2003, and 0-14 years old children predominated. Data from the case-control study indicated that illness was associated with drinking water from community water system. Also the laboratory examination demonstrated contamination of different water samples with the epidemic virus serotypes and sequence analysis showed high level of genetic similarity between waterborne and clinical isolates. For these reasons the outbreak should be classified as a waterborne one. Phylogenetic reconstruction showed that all Belarusian ECHO 30 isolates belong to the major genotype of ECHO 30 which has been circulating for last 15 years in Europe and North America. Viral agents of 2003 were very similar and substantially differed from isolates of 1997. Comparison of nucleotide sequences of isolates from myocarditis patients revealed their considerable genetic similarity with $\mathrm{ECHO} 30$ isolates from patients with aseptic meningitis and from water. The results of the study draw attention to the importance of virological control of tap and bottled water as a relevant measure aimed at reduction of epidemiological risks.
\end{abstract}

Key words: enterovirus, enterovirus infection outbreak, phylogenetic analysis, waterborne transmission

Address for correspondence: T. V. Amvrosieva, Research Institute for Epidemiology and Microbiology, 23, Philimonov str., 220114, Minsk, Republic of Belarus. E-mail: labsanvir@gmail.com

\section{INTRODUCTION}

Enteroviruses (EV) are widespread human pathogens causing a broad spectrum of diseases ranging from mild, asymptomatic ones to severe disorders with possibility of long-term effects (1). Genetic variability is a potential for rapid enterovirus evolution that in turn leads to appearance of new antigenic virus variants being able to avoid immune protection (2). The great part of genus Enterovirus is characterized by epidemic mode of transmission causing numerous outbreaks routinely registered all over the world. Due to dynamics of the modern society enteroviruses easily spread through the human population and the very same serotypes almost simultaneously infect people from geographically distant countries. For the last decade epidemiological surveillance services reported numerous enterovirus outbreaks in different countries - USA, Canada, France, Finland, Germany, Belgium, Romania, Poland, Spain, Russia, Ukraine (3-10). During the same period enterovirus outbreaks were registered in all of six districts of Belarus. Two of them, reported in 1997 (in Gomel) and in 2003 (in Minsk), were the most extensive and involved 461 and 1,351 patients respectively. Virus ECHO 30 was identified as the dominant etiologic agent of the outbreak in 1997 (11) whereas co-circulation of ECHO 30, ECHO 6 and Coxsackievirus B5 took place in 2003. The massive outbreak in 2003 was preceded by local outbreaks caused by the very same viruses and registered one-two months before in geographically distant regions of the country (Brest and Minsk regions).

The aims of the present study were to characterize clinical and epidemiologic features of the outbreak in Belarusian capital city of Minsk in 2003, to elucidate phylogenetic relationships of outbreak causative agents and to assess the possibility of waterborne virus transmission.

\section{MATERIALS AND METHODS}

\section{Epidemiological Investigation}

To determine risk of enterovirus infection associated with consumption of drinking water from community water system a matched case-control study was conducted. The cases included 1,222 patients from group of children (aged $<15$ ) with diagnosis of enteroviral infection. The controls included 564 healthy chil- 
dren (aged < 15) from the same households. The epidemiological data were analyzed using EpiInfo v.6. Odds ratio (OR) and 95\% confidence interval (CI) were calculated.

\section{Collection and Processing of Clinical and Environmental Specimens}

Clinical specimens were collected from children and adult patients who underwent treatment in Minsk hospitals between July and November 2003. Altogether 1056 specimens of cerebrospinal fluids (CSFs), 105 faeces specimens, 39 nasopharyngeal swabs and 242 serum specimens were examined.

Environmental samples of surface and tap water were collected during the outbreak from artificial and natural reservoirs in recreation areas (10 samples) and community water system (110 samples including 32 samples from the foci of infection). In addition 63 assays of bottled drinking water were performed. Processing of water samples and concentrating of viruses were carried out by filtration of different volumes (100 1 - for surface and 10001 - for drinking water) through inorganic filter and virus elution with $3 \%$ beef extract solution.

\section{Virus Isolation and Identification}

Enteroviruses from clinical and environmental samples were isolated by thrice-repeated propagation in cell cultures (BGM, $\mathrm{RD}$, Hep-2c) and identified by conventional neutralization test with WHO antiserum pools A to $\mathrm{H}$ (12). Obtained virus isolates were collected and stored at $-20^{\circ} \mathrm{C}$.

\section{Detection of Antienterovirus Antibodies in Serum Speci- mens}

The presence of neutralizing antibodies to each of epidemic enterovirus serotypes (ECHO 6, ECHO 30, Coxsackie B5) in patient's sera was detected as follows: serum samples were diluted 1: 10 and mixed with equal volumes of enterovirus isolates $\left(10^{2}\right.$ $\mathrm{TICD}_{50} / \mathrm{ml}$ ) obtained during the outbreak. After one-hour preincubation at $37^{\circ} \mathrm{C}$ mixtures inoculated cell cultures (BGM, RD, Hep-2c). Inoculated flacks were incubated during 7 days and daily examined for viral cytodestruction. An inhibition of cytopathic effect by serum was an evidence of the presence of neutralizing antibodies to enterovirus serotype in that sample.

Immunoglobulins $M$ to enterovirus in serum samples were detected by ELISA with commercial kit manufactured by BRIEM (Belarus).

\section{Viral RNA Extraction, Reverse Transcription and PCR}

Enteroviral RNA from clinical, environmental samples and virus isolates was extracted with TRI-reagent (SIGMA) and chloroform followed by isopropanol precipitation. RT-PCR (reverse transcription-polymerase chain reaction) was accomplished according to four different protocols depending on the aim of investigation. For detection of enteroviruses in clinic and water samples, RT-PCR and one tube nested RT-PCR with primers targeted to 5'UTR of enteroviral genome was performed as described previously $(13,14)$. Infectious properties of waterborne enteroviruses were evaluated by integrated cell culture PCR (15) with the very same primers. For direct sequencing of RT-PCR products, cDNA of virus isolates were amplified with primers to VP1-coding region of enterovirus genome (16). Negative controls were added on the stages of RNA extraction, reverse transcription and PCR amplification to exclude contamination of the samples or reaction mixtures as the source of false positive results.

\section{Nucleotide Sequencing of PCR Products and Sequence Analysis}

Nucleotide sequencing of RT-PCR products was performed with "Thermo Sequenase Cy5 Dye Terminator Cycle sequencing Kit" according to the instruction of the manufacturer (Amersham Biosciences). After completion of the cycle sequencing reactions the products were analyzed with ALFexpress II DNA Analyzer (Amersham Biosciences). The GenBank DNA sequence library was screened for similar sequences using the BLAST program (17). Nucleotide sequences were multiple aligned with Clustal W (18), compared with one another and with enterovirus sequences from GenBank database. The comparative analysis of the sequences was made with the MEGA computer program, version 3 (19). To account for the multiple nucleotide substitutions, the pairwise genetic distances were calculated by Tamura-Nei's model of sequence evolution (20). An unrooted dendrogram was reconstructed from the genetic distances by the Neighbor-joining method (21) as implemented in the MEGA computer program.

\section{RESULTS}

\section{Epidemiological Investigation}

From July, 27 to November, 9, altogether 1,351 patients (78.65/100,000 population) with clinical manifestation of enteroviral infection underwent treatment in hospitals of Belarusian capital city of Minsk. Following final diagnoses were established: aseptic meningitis $(57.5 \%)$, herpangina (18.1\%), encephalitis $(8.8 \%)$, and enteric disorders $(6.3 \%)$. Another $8.8 \%$ of patients developed feebly marked and unspecific symptoms of disease. In about $10 \%$ of patients myocardial disorders were observed. According to severity of clinical course $92.1 \%$ of cases were classified as middle (1,109 patients), 3.3\% (45 patients) - mild and $14.6 \%$ - severe (197 patients).

Analysis of the temporal dynamics of the outbreak (Fig.1) showed isolated instances of disease cases ( 2 to 9 per day) during 30-32 ${ }^{\text {nd }}$ weeks of 2003 (1.46-1.86/100,000 population). Prominent rise started at $33^{\text {rd }}$ week of 2003, continued over four weeks (two incubation periods) and reached the peak of 28 cases per day by $36^{\text {th }}$ week of 2003 (11.6/100,000 population). Despite minor decrease during two following weeks the attack rate was kept high until $39^{\text {th }}$ week (about 10/100,000 population) then followed by gradual decline.

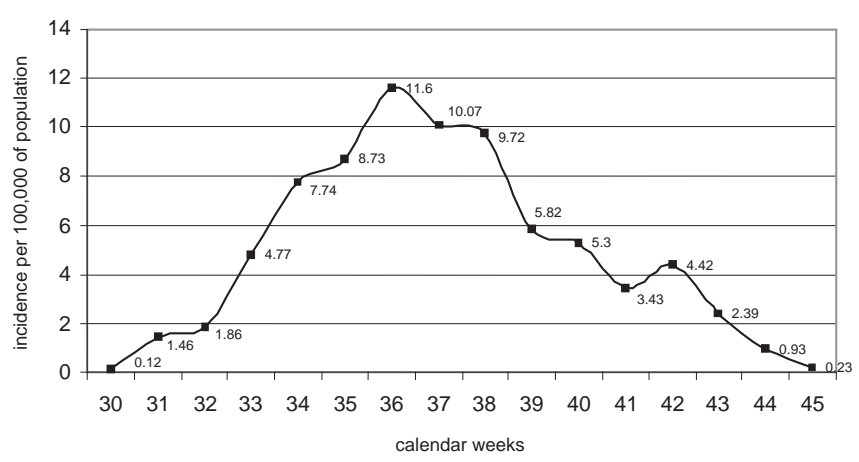

Fig.1. Temporal dynamics of the enterovirus infection morbidity rate in Minsk in 2003. 
Most affected age group during the outbreak (Fig.2) were children 0-14 years old (90.5\%) with different distribution of absolute and relative number of cases: the maximum attack rate was registered among 3-6 years old children $(95.3 / 100,000)$ whereas the highest absolute number of cases was in the age group of 7-14 (572 cases, $42.3 \%$ of all patients). Among adult patients the highest incidence rate (0.64/10000 population) and absolute number ( 92 patients) was found in adolescents.

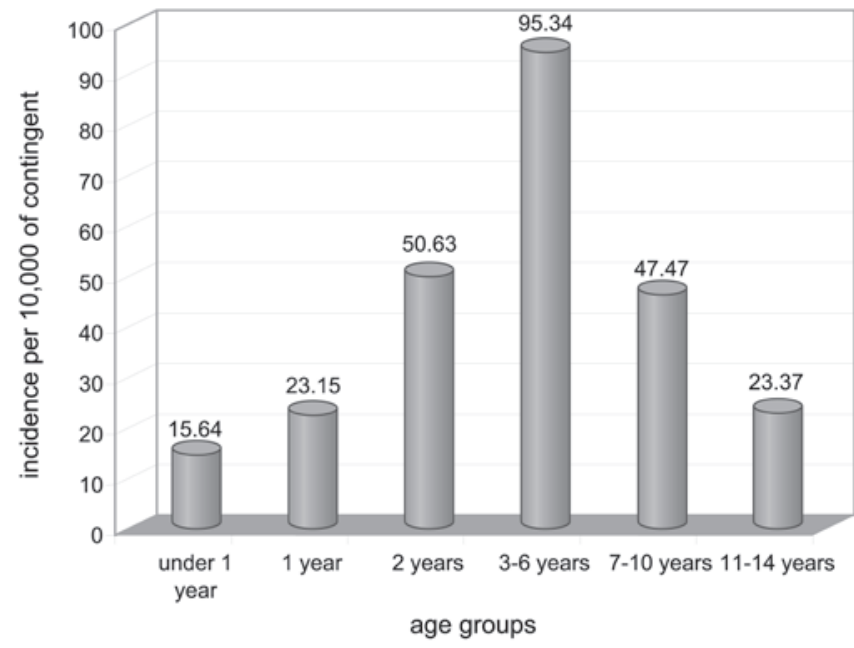

Fig. 2. Age distribution of enteroviral infection morbidity among children aged 0-14.

Single foci of infection were registered in $95.6 \%(n=1,233)$, multiple - in $4.4 \%(n=57)$ of households. In the majority of multiple foci new cases of disease appeared simultaneously (index of simultaneous focus appearance was equal to 2.5).

Data from the case-control study indicated that illness was associated with drinking water from community water system $(\mathrm{OR}=1.37 ; 95 \% \mathrm{CI}: 1.08$ to $1.74, \mathrm{p}=0.008)$.

\section{Laboratory Investigation}

Patients with aseptic meningitis and meningeal symptoms $(\mathrm{n}=1051)$ were examined for the presence of enterovirus RNA in CSF. Enteroviral RNA was detected in $51.6 \%$ of CSF specimens (from $48.1 \%$ at the initial stage to $89.3 \%$ of samples at the peak of the outbreak). Serological investigation revealed IgM to enterovirus in $49.7 \%$ of adult patients $(n=151)$ and in $71.4 \%$ of children $(n=91)$. Detection of enterovirus RNA in nasopharyngeal swabs from patients with respiratory symptoms $(n=31)$ resulted in $32.3 \%$ positive samples. Patients with myocardial symptoms $(n=45)$ were grouped and examined separately from others. Three samples (CSF, nasopharyngeal swab and serum) from each patient were collected and enterovirus RNA was detected by one tube nested PCR. Positive results were obtained in $60.52 \%$ of CSFs, $35.0 \%$ of nasopharyngeal swabs and in $20.0 \%$ of sera for that group of patients. Diagnosis of enteroviral infection was laboratory confirmed for $71.1 \%$ of patients with myocardial disorders.

Altogether 32 enterovirus isolates were recovered from 24 faeces samples, 7 CSFs and 1 nasopharyngeal swab. According to results of neutralization test enterovirus isolates were identified as ECHO 30 (60\%), ECHO 6 (24\%) and Coxsackie B5 (24\%).

To elucidate a relative contribution of different enterovirus serotypes to morbidity during the outbreak the presence of neut- ralizing antibodies to each of three serotypes was examined in randomly sampled sera from 91 patients. Neutralizing antibodies to ECHO 30 isolates were found in $100.0 \%$, ECHO 6 - in $40.7 \%$ and Coxsackie B5 - in $30.3 \%$ of samples. These data showed that all three serotypes of viruses were etiologic agents of the outbreak with ECHO 30 predomination.

To assess the level of virus contamination of water samples from surface reservoirs of recreation areas, community water system (sampled before hyperchlorination at the initial stage of the outbreak) and bottled drinking water were examined. Enterovirus RNA was revealed in $28.2 \%$ of tap water samples $(n=110)$ including $43.85 \%$ of samples taken from the foci of infection $(n=32)$ (Fig. 3). Examination of enteroviral RNA in bottled drinking water $(n=63)$ showed $20.6 \%$ positive samples. Ten samples were collected from water reservoirs in recreation areas and enterovirus RNA was found in three of them $(30.3 \%)$.

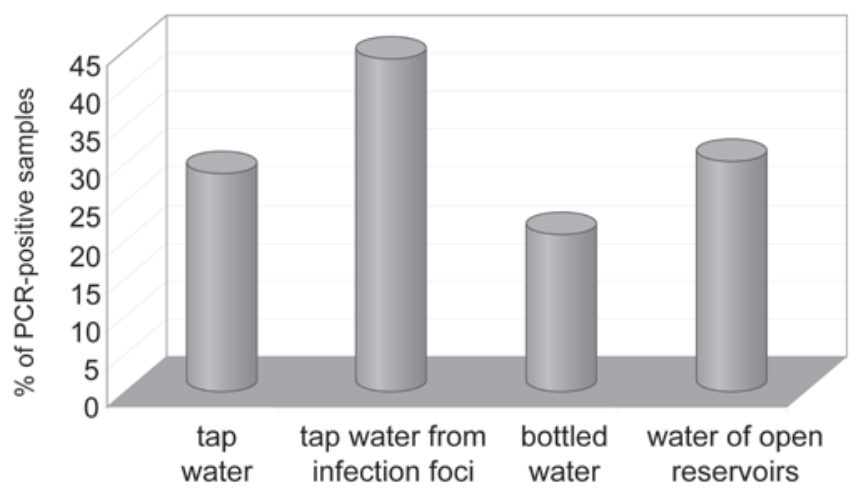

Fig. 3. Detection of enteroviral RNA in different water samples.

Positive for enterovirus RNA water specimens were investigated for the presence of infectious viral agents by integrated cell culture PCR. After samples inoculation on three different cell lines (BGM, RD, Hep2c) and five-day incubation of cells they were harvested and examined for the presence of enteroviral negative strain RNA. An evidence of virus replication was obtained for seventeen samples. The level of positive findings for tap water was $9.1 \%$, bottled drinking water $-7.9 \%$, surface water $-20.0 \%$ of samples. Following propagation of positive samples resulted in virus isolation from 7 of them. All virus isolates were recovered from tap water samples and identified as ECHO 30 (71.4\%), ECHO 6 (14.3\%) and Coxsackie B5 $(14.3 \%)$. Isolation of viable virus from ten samples containing enteroviral negative strain RNA (including bottled and surface water) was unsuccessful.

\section{Sequence Analysis and Phylogenetic Reconstruction}

Because of unsuccessful virus isolation molecular typing by direct nucleotide sequencing of PCR products was carried out to identify etiologic agents from myocardial patients. Nucleotide sequences were obtained from clinical specimens (No. $1,092,1,260,1,501$ and 1,993) collected during the outbreak and compared with the known prototype strain sequences from GenBank. Three of nucleotide sequences had highest similarity scores with Bastianni prototype strain of ECHO 30, and one of them was the most similar to ECHO 6 prototype strain Burgess (Table 1). 
Table 1. Results of molecular typing of enteroviruses from myocarditis patients

\begin{tabular}{|c|c|c|c|c|c|c|}
\hline \multirow[b]{2}{*}{ Sample number } & \multicolumn{2}{|c|}{ Highest-scoring prototype } & \multicolumn{2}{|c|}{ Second-highest-scoring prototype } & \multirow{2}{*}{$\begin{array}{c}\text { Result } \\
\text { of molecular } \\
\text { typing }\end{array}$} & \multirow[b]{2}{*}{$\begin{array}{l}\text { Neutralization } \\
\text { type }\end{array}$} \\
\hline & Type & $\begin{array}{l}\text { \% sequence } \\
\text { identity }\end{array}$ & Type & $\begin{array}{l}\text { \% sequence } \\
\text { identity }\end{array}$ & & \\
\hline 1260 & $\begin{array}{c}\text { E30 } \\
\text { Bastianni }\end{array}$ & 82.6 & $\begin{array}{c}\text { E21 } \\
\text { Farina }\end{array}$ & 63.1 & $\mathrm{ECHO} 30$ & $\mathrm{ECHO} 30$ \\
\hline 1993 & $\begin{array}{c}\text { E30 } \\
\text { Bastianni }\end{array}$ & 82.6 & $\begin{array}{c}\text { E21 } \\
\text { Farina }\end{array}$ & 63.1 & $\mathrm{ECHO} 30$ & $\mathrm{ECHO} 30$ \\
\hline $1501^{*}$ & $\begin{array}{c}\text { E30 } \\
\text { Bastianni }\end{array}$ & 81.9 & $\begin{array}{c}\text { E21 } \\
\text { Farina }\end{array}$ & 60.1 & $\mathrm{ECHO} 30$ & - \\
\hline $1092^{*}$ & $\begin{array}{c}\text { E6 } \\
\text { Burgess }\end{array}$ & 75.1 & $\begin{array}{c}\text { E24 } \\
\text { De Camp }\end{array}$ & 56.1 & ECHO 6 & - \\
\hline
\end{tabular}

* - unsuccessful virus isolation from patient's sample

To elucidate the molecular mechanisms underlying enterovirus epidemiology in Belarus, we investigated phylogenetic relations of Belarusian isolates of ECHO 30, ECHO 6 and Coxsackie B5 collected between 1997 and 2004. A phylogenetic tree based upon nucleotide sequences of 25 Belarusian enterovirus isolates (Table 2) as well as 26 enterovirus strains sequences from GenBank is depictured on Fig. 4.

All sequences formed three common clusters with their prototype strains - Bastianni, Burgess and Faulkner. Molecular evidence of the waterborne virus transmission was obtained by comparison of nucleotide sequences from clinical and water borne virus isolates. Genetic distances were calculated and revealed a very little sequence divergence between enteroviruses of the same serotype recovered during Minsk outbreak in 2003 from clinical samples and tap drinking water (Table 2): for ECHO 30 - up to 0.015 , for ECHO $6-0.017$, for Coxsackievirus B5 - 0.005 . High rates of sequence similarity between clinical and water borne isolates of ECHO 30, ECHO 6 and Coxsackie B5 viruses indicate that drinking water could be involved in enterovirus spreading in the exposed human population during the outbreak.

Table 2. List of Belarusian enterovirus isolates

\begin{tabular}{|c|c|c|c|c|}
\hline No. & Registration number & Source of isolation & Time and place of isolation & Virus serotype \\
\hline 1 & 17363 & Aseptic meningitis patient (CSF) & 1997, Gomel & $\mathrm{ECHO} 30$ \\
\hline 2 & 19016 & Tap water & 1997, Gomel & $\mathrm{ECHO} 30$ \\
\hline 3 & 19411 & Tap water & 1997, Gomel & $\mathrm{ECHO} 30$ \\
\hline 4 & 1260 & Myocarditis patient (faeces) & 2003, Minsk & $\mathrm{ECHO} 30$ \\
\hline 5 & 1275 & Aseptic meningitis patient (faeces) & 2003, Minsk & $\mathrm{ECHO} 30$ \\
\hline 6 & 1553 & Aseptic meningitis patient (CSF) & 2003, Minsk & $\mathrm{ECHO} 30$ \\
\hline 7 & 1993 & Myocarditis patient (n/ph swab) & 2003, Minsk & $\mathrm{ECHO} 30$ \\
\hline 8 & 2057 & Aseptic meningitis patient (faeces) & 2003, Minsk & $\mathrm{ECHO} 30$ \\
\hline 9 & 2065 & Tap water & 2003, Minsk & $\mathrm{ECHO} 30$ \\
\hline 10 & 2070 & Tap water & 2003, Minsk & $\mathrm{ECHO} 30$ \\
\hline 11 & 2509 & Aseptic meningitis patient (CSF) & 2003, Minsk & $\mathrm{ECHO} 30$ \\
\hline 12 & 2698 & Well water & 2003, Minsk region & ECHO 30 \\
\hline 13 & 2703 & Aseptic meningitis patient (CSF) & 2003, Minsk region & $\mathrm{ECHO} 30$ \\
\hline 14 & 2704 & Aseptic meningitis patient (CSF) & 2003, Minsk region & ECHO 30 \\
\hline 15 & 3163 & Aseptic meningitis patient ( $\mathrm{n} / \mathrm{ph}$ swab) & 2003, Brest region & $\mathrm{ECHO} 30$ \\
\hline 16 & 3165 & Aseptic meningitis patient (faeces) & 2003, Brest & $\mathrm{ECHO} 30$ \\
\hline 17 & 3329 & Enterovirus infection patient (faeces) & 2004, Minsk & $\mathrm{ECHO} 30$ \\
\hline 18 & 2053 & Aseptic meningitis patient (faeces) & 2003, Minsk & $\mathrm{ECHO} 6$ \\
\hline 19 & 2341 & Aseptic meningitis patient (CSF) & 2003, Minsk & $\mathrm{ECHO} 6$ \\
\hline 20 & 32477 & Sewage water & 2001, Minsk & $\mathrm{ECHO} 6$ \\
\hline 21 & 1574 & Tap water & 2003, Minsk & $\mathrm{ECHO} 6$ \\
\hline 22 & 1841 & Aseptic meningitis patient (CSF) & 2003, Minsk & Coxsackie B5 \\
\hline 23 & 1009 & Tap water & 2003, Minsk & Coxsackie B5 \\
\hline 24 & 3167 & Enterovirus infection patient (faeces) & 2003, Brest region & Coxsackie B5 \\
\hline 25 & 371 & Sewage water & 1998, Minsk region & Coxsackie B5 \\
\hline
\end{tabular}




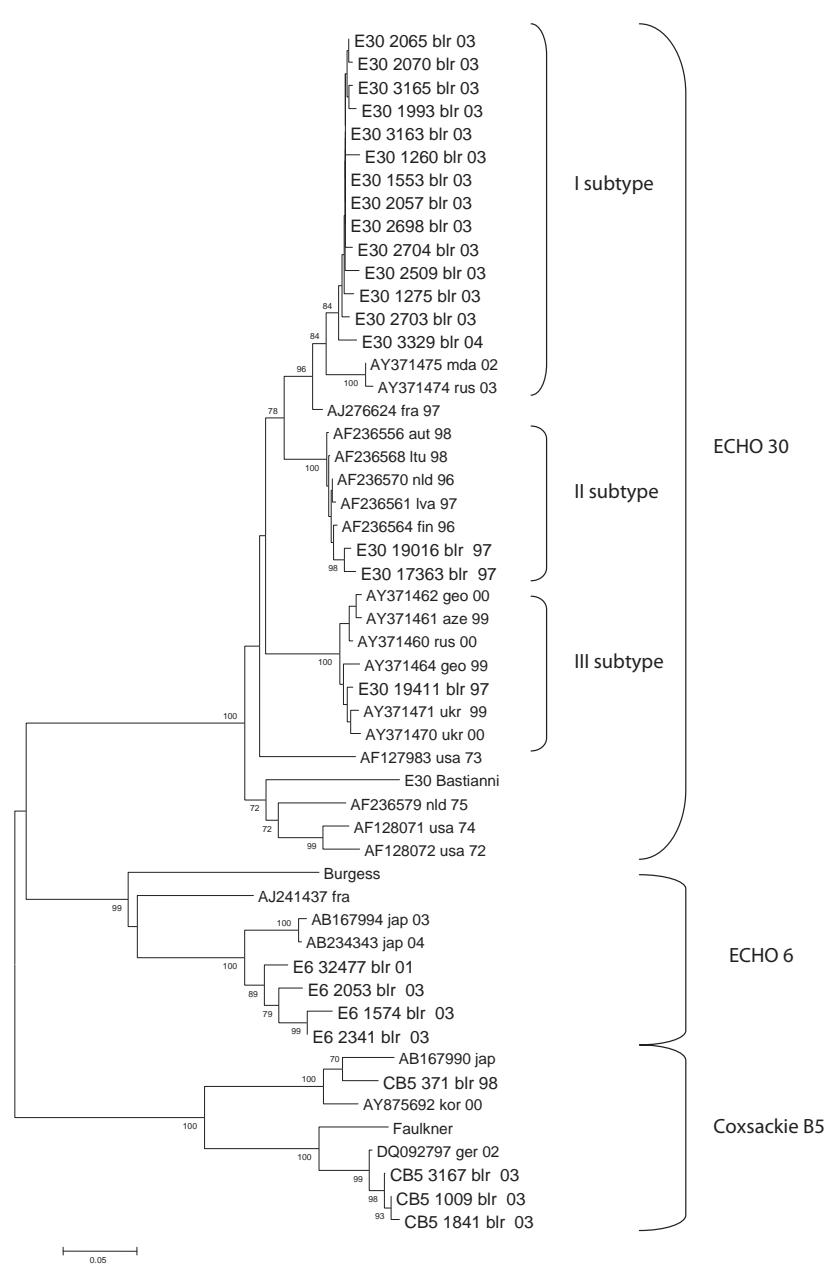

Fig. 4. Phylogenetic relations of Belarusian enterovirus isolates. Phylogram based on partial VP1 (456 b.p.) sequences. Neighbor-joining tree was evaluated with 1000 bootstrap pseudoreplicates. The scale bar represents the genetic distance (nucleotide substitutions per site).

All examined sequences from Belarusian ECHO 30 isolates together with GenBank ECHO 30 sequences collected for last 15 years fell into a single cluster different from Bastianni and previously collected ECHO 30 strains by 0.152 . Within that cluster Belarusian isolates of 1997 and 2003 were members of three different subclusters. Average genetic distance between sequences of the first and second subclusters was 0.084 , the second and the third -0.105 , the first and the third -0.123 . Nucleotide sequences from 13 ECHO 30 isolates collected in June - September of 2003 and in August of 2004 were members of the first subcluster whereas the second and the third subclusters included two and one of 1997 ECHO 30 isolates respectively. Maximum of genetic distances between 1997 and 2003 Belarusian ECHO 30 isolates was 0.126. Two Belarusian 1997 ECHO 30 isolates (No. 19,016 and 17,363 ) were very similar and differed by 0.106 from No. 19,411 that was collected in the same time and in the same area of the country. On the contrary to 1997 Belarusian ECHO 30 isolates, all 2003 ECHO 30 (including viruses from myocardial patients, No. 1,260, 1,993) from geographically distant regions of the country (Minsk and Brest regions) were different by maximum of 0.017 and formed monophyletic group within the first subcluster. Moreover genetic distance between 2003 ECHO 30 isolates and ECHO 30 virus that was obtained in the next year after the outbreak did not exceed 0.027. Comparison with GenBank previously published sequences revealed that sequences of ECHO 30 isolates from Moldova, 2002 and Russia, 2003 (10) were the closest to Belarusian 2003-2004 ECHO 30 with the maximum of sequence divergence among them - 0.056. Belarusian 1997 ECHO 30 isolates were divided between two groups: "west" and "east". The "West" group formed the second subcluster and included besides two 1997 Belarusian ECHO 30 isolates (No. 19,016 and 17,363) viruses from Western-Europe countries collected between 1996 and 1998 (22), whereas the members of the "east" group (the third subcluster) were ECHO 30 isolates from Ukraine, Georgia, Russia, Azerbaijan (1999-2000) (10) and the single 1997 Belarusian ECHO 30 isolate No. 19,411.

\section{DISCUSSION}

Etiologic agents of the outbreak in the Belarusian capital city of Minsk (ECHO 6, Coxsackievirus B5 and ECHO 30) were the very same serotypes that caused outbreaks in different European countries and USA as it has been recently published (4-10, 23, 24). The last reported ECHO 30 outbreaks were in Romania (1999) (24), Belgium (2000) (5), and France (2000), when simultaneous co-circulation of ECHO 30, ECHO 6 and ECHO 13 was reported (9). Previous large ECHO 30 outbreak took place in Belarusian city of Gomel in 1997 (11).

Analysis of clinical manifestations during the Minsk outbreak revealed unusually high rate of severe clinical forms of infection including encephalitis in $8.8 \%$ and myocardial disorders in about $10.0 \%$ of patients, whereas mild infections were registered only in $3.3 \%$ of patients. Enteroviral etiology of disease in myocardial patients was confirmed by RT-PCR in $71.1 \%$ of cases. The presence of Coxsackievirus B5 in spectrum of isolated viruses suggested that Coxsackievirus B5 might be the etiologic agent in myocardial patients. However, results of sequencing of four randomly sampled clinical specimens revealed presence of ECHO 30 in three and ECHO 6 - in one of them. Obtained results pointed out at possible involvement of echoviruses in myocardial complication during the Minsk outbreak in 2003.

Epidemiologic observation (season and age distribution) was typical for enterovirus epidemics in temperate climates: the peak of the outbreak occurred during summer-autumn period of 2003, with 0-14 years old children affected utmost. High level of simultaneously appeared new cases in multiple foci of infection and short onset period of the outbreak with synchronous involving of people from different city districts led to assumption about common source of virus spreading. Laboratory examination revealed considerable portion of drinking water samples being contaminated with the epidemic virus serotypes. Obtained epidemiological data showed that illness was associated with consumption of drinking water from community water system. Results of phylogenetic analysis were in agreement with these data and revealed high levels of genetic similarity between waterborne and clinical isolates. Taken together these findings indicate that outbreak of enteroviral infection in the Belarusian capital city of Minsk should be classified as a waterborne outbreak.

Despite proved causative role of the three different enterovirus serotypes (ECHO 30, ECHO 6 and Coxsackie B5) our findings showed ECHO 30 predomination at the time of the outbreak. In 
addition ECHO 30 was the main etiologic agent of the enterovirus outbreaks registered in different regions of Belarus before the Minsk outbreak in June-July of 2003 and in 1997. For these reasons molecular epidemiology of ECHO 30 was investigated more thoroughly. Results of phylogenetic analysis showed that sequences of all Belarusian ECHO 30 isolates belong to the major genotype of ECHO 30 which has been circulating for last 15 years in countries of Europe and North America $(22,25)$ : the maximum of genetic distances between them did not exceed 0.140. Belarusian ECHO 30 isolates of 1997 and 2003 got into three different subclusters corresponding to the three virus subtypes. The data are in agreement with previously reported pattern of ECHO 30 molecular epidemiology (22) showing succession of dominant sublineages within a single genotype.

All Belarusian 2003 ECHO 30 isolates from geographically distant regions were very similar and formed monophyletic group within the first subcluster. Our data demonstrate lack of genetic heterogeneity of viruses circulating in 2003 in Minsk and other regions of Belarus. Moreover an ECHO 30 isolate of the following 2004 year grouped with isolates of 2003 indicating circulation of the same virus subtype in the next year after the outbreak. Comparative analysis with GenBank sequences displayed that the subtype of ECHO 30 being an etiologic agent of the outbreak in 2003 did not arise newly but had circulated before in neighbouring countries [Moldova, 2002 and Russia, 2003 (10)].

Unlike Belarusian 2003-2004 isolates which were closely related, viruses collected during the enterovirus outbreak in 1997 were genetically diverse according to the results of phylogenetic reconstruction: two ECHO 30 isolates of 1997 were members of the second subcluster and one belonged to the third subcluster. These data stand for circulation of two ECHO 30 subtypes at the time of outbreak in 1997. Simultaneous circulation of different ECHO 30 subtypes was previously registered in France in 2000 (23). Interestingly that ECHO 30 isolates No. 19,016 and 17,363 were related to viruses circulating in West-European countries one-two years before the outbreak whereas ECHO 30 isolate No. 19,411 belonged to subtype of ECHO 30 that circulated in eastern countries in two-three years after 1997.

Two of the eight investigated 2003 ECHO 30 isolates (No. 1,993 and 1,260 ) were acquired from myocarditis patients. Comparison of nucleotide sequences and following phylogenetic analysis of these two isolates revealed their considerable genetic similarity with ECHO 30 isolates from patients with aseptic meningitis and from water. Taken together with clinical observations showing unusually high rate of cardiac complication in patients these data indicate the presence of cardiovirulent properties in ECHO 30 subtype that caused outbreak in 2003. Moreover, molecular epidemiology data permit to suppose waterborne transmission not only of enteroviral meningitis but cardiac disorders as well. The findings lead to assumption that population of patients with enteroviral heart infection may be part of the cohort of diseased people affected during waterborne outbreaks. Some of these people may later develop severe cardiac disorders including myocarditis and dilated cardiomyopathy.

The results of this study accentuate the fact that existent watersupply systems in cities with surface water as a source, including Minsk, may be extremely vulnerable in the context of potential viral contamination. At present time commonly used procedures of water refinement and disinfection on water inlet structures do not guarantee epidemiological safety of water with respect to human pathogenic viruses. Obtained data on enterovirus detection in bottled drinking water during the outbreak along with previously reported findings of Norwalk-like viruses in mineral water (26) draw attention to the problem of bottled water contamination by enteric viruses as a potential way of virus transmission.

In view of the aforesaid intensification of city water supply systems surveillance becomes a problem of urgent importance (especially in cities with surface waterbodies as a source). Implementation of regular and strict quality control of tap and bottled water considering virus contamination may be a relevant measure aimed at reduction of epidemiological risks.

\section{REFERENCES}

1. Melnick J. Enteroviruses: polioviruses, coxsackieviruses, echoviruses, and new enteroviruses. In: Fields BN, Knipe DM, Howley PM, editors. Fields Virology, 3rd ed. Philadelphia: Lippincott - Raven Publishers; 1996. p. 655-712.

2. Domingo E, Escarmis C, Sevilla N, Moya A, Elena SF, Quer J, et al. Basic concepts in RNA virus evolution. FASEB J. 1996 Jun;10(8):859-64.

3. Drebot MA, Nguan CY, Campbell JJ, Lee SH, Forward KR. Molecular epidemiology of enterovirus outbreaks in Canada during 1991-1992: identification of echovirus 30 and coxsackievirus B1 strains by amplicon sequencing. J Med Virol. 1994 Dec;44(4):340-7.

4. Wang JR, Tsai HP, Huang SW, Kuo PH, Kiang D, Liu CC. Laboratory diagnosis and genetic analysis of an echovirus 30-associated outbreak of aseptic meningitis in Taiwan in 2001. J Clin Microbiol. 2002 Dec;40(12):4439-44.

5. Thoelen I, Lemey P, Van Der Donck I, Beuselinck K, Lindberg AM, Van Ranst M. Molecular typing and epidemiology of enteroviruses identified from an outbreak of aseptic meningitis in Belgium during the summer of 2000. J Med Virol. 2003 Jul;70(3):420-9.

6. Centers for Disease Control and Prevention. Outbreaks of aseptic meningitis associated with echoviruses 9 and 30 and preliminary surveillance reports on enterovirus activity-United States, 2003. MMWR Morb Mortal Wkly Rep. 2003 Aug 15;52(32):761-4.

7. Majda-Stanislawska E, Kuydowicz J, Bartczak D. Epidemic of ECHO type 30 virus meningitis in children from the Lodz region in the years 1995 and 1996. Przegl Epidemiol. 1997;51(3):267-74. (In Polish.)

8. Lopez Alcala MI, Rodriguez Priego M, de la Cruz Morgado D, Barcia Ruiz JM. Outbreak of meningitis caused by echovirus type 30. An Esp Pediatr. 1997 Mar;46(3):237-40. (In Spanish.).

9. Chomel JJ, Antona D, Thouvenot D, Lina B. Three ECHOvirus serotypes responsible for outbreak of aseptic meningitis in Rhone-Alpes region, France. Eur J Clin Microbiol Infect Dis. 2003 Mar;22(3):191-3.

10. Lukashev AN, Ivanova OE, Eremeeva TP, Lashkevich VA, Chernenko KE. Molecular epidemiology of the ECHO 30 virus in Russia and CIS countries. Vopr Virusol. 2004 Sep-Oct;49(5):12-6. (In Russian.)

11. Amvrosieva TV, Titov LP, Mulders M, Hovi T, Dyakonova OV, Votyakov VI, et al. Viral water contamination as the cause of aseptic meningitis outbreak in Belarus. Cent Eur J Public Health. 2001 Aug;9(3):154-7.

12. Melnick JL, Rennick V, Hampil B, Schmidt NJ, Ho HH. Lyophilized combination pools of enterovirus equine antisera: preparation and test procedures for the identification of field strains of 42 enteroviruses. Bull World Health Organ. 1973;48(3):263-8.

13. Wessely R, Henke A, Zell R, Kandolf R, Knowlton KU. Low-level expression of a mutant coxsackieviral cDNA induces a myocytopathic effect in culture: an approach to the study of enteroviral persistence in cardiac myocytes. Circulation. 1998 Aug 4;98(5):450-7.

14. Poklonskaia NV, Amvros'eva TV, D‘iakonova OV, Shcherbakova OB, Voilokova RI. Modified nested polymerase chain reaction in one tube for detection of Enterovirus. Klin Lab Diagn. 2004 Apr;(4):46-7.

15. Reynolds KA, Gerba CP, Abbaszadegan M, Pepper LL. ICC/PCR detection of enteroviruses and hepatitis A virus in environmental samples. Can J Microbiol. 2001 Feb;47(2):153-7.

16. Oberste MS, Maher K, Kilpatrick DR, Pallansch MA. Molecular evolution of the human enteroviruses: correlation of serotype with VP1 sequence and application to picornavirus classification. J Virol. 1999 Mar;73(3):1941-8. 
17. Altschul SF, Gish W, Miller W, Myers EW, Lipman DJ. Basic local alignment search tool. J Mol Biol. 1990 Oct 5;215(3):403-10.

18. Thompson JD, Higgins DG, Gibson TJ, CLUSTAL W: improving the sensitivity of progressive multiple sequence alignment through sequence weighting, position-specific gap penalties and weight matrix choice. Nucleic Acids Res. 1994 Nov 11;22(22):4673-80.

19. Kumar S, Tamura K, Nei M. MEGA3: Integrated software for molecular evolutionary genetics analysis and sequence alignment. Brief Bioinform. 2004 Jun;5(2):150-63.

20. Tamura K, Nei M. Estimation of the number of nucleotide substitutions in the control region of mitochondrial DNA in humans and chimpanzees. Mol Biol Evol. 1993 May;10(3):512-26.

21. Saitou N, Nei M. The neighbor-joining method: a new method for reconstructing phylogenetic trees. Mol Biol Evol. 1987 Jul;4(4):406-25.

22. Savolainen C, Hovi T, Mulders MN. Molecular epidemiology of echovirus 30 in Europe: succession of dominant sublineages within a single major genotype. Arch Virol. 2001;146(3):521-37.
23. Bailly JL, Brosson D, Archimbaud C, Chambon M, Henquell C, PeigueLafeuille H. Genetic diversity of echovirus 30 during a meningitis outbreak, demonstrated by direct molecular typing from cerebrospinal fluid. J Med Virol. 2002 Dec;68(4):558-67.

24. Cernescu C, Tardei G, Ruta S, Bleotu C, Alexiu I, Jucu V. An outbreak of aseptic meningitis due to ECHO 30 virus in Romania during the 1999 summer. Rom J Virol. 1999 Jan-Dec;50(1-4):99-106.

25. Oberste MS, Maher K, Kennett ML, Campbell JJ, Carpenter MS, Schnurr $\mathrm{D}$, et al. Molecular epidemiology and genetic diversity of echovirus type 30 (E30): genotypes correlate with temporal dynamics of E30 isolation. J Clin Microbiol. 1999 Dec;37(12):3928-33.

26. Beuret C, Kohler D, Baumgartner A, Lüthi TM. Norwalk-like virus sequences in mineral waters: one-year monitoring of three brands. Appl Environ Microbiol. 2002 Apr;68(4):1925-31

Received October 24, 2005 Received in revised form and accepted January 3, 2006 